\title{
On Predictability of Revisioning in Corporate Cash Flow Forecasting
}

\author{
Florian Knöll \\ Institute of Information Systems \\ and Marketing, Karlsruhe Institute \\ of Technology, Germany \\ knoell@kit.edu
}

\author{
Thomas Setzer \\ Institute of Information Systems \\ and Marketing, Karlsruhe Institute \\ of Technology, Germany \\ thomas.setzer@kit.edu
}

\author{
Kevin Laubis \\ FZI Research Center for \\ Information Technology, Germany \\ laubis@fzi.de
}

\begin{abstract}
Financial services within corporations usually are part of an information system on which many business functions depend. As of the importance of forecast quality for financial services, means of forecast accuracy improvement, such as data-driven statistical prediction techniques and/or forecast support systems, have been subject to IS research since decades. In this paper we consider means of forecast improvement due to regular patterns in forecast revisioning. We analyze how business forecasts are adjusted to exploit possible improvements for the accuracy of forecasts with lower lead time. The empirical part bases on an unique dataset of experts' cash flow forecasts and accountants' actuals realizations of companies in a global corporation. We find that direction and magnitude of the final revision in aggregated forecasts can be related to suggested targets in earnings management, providing the means of improving the accuracy of longer-term cash flow forecasts.
\end{abstract}

\section{Introduction}

Corporate financial planning services and subsequent management activities in globally operating enterprises typically rely on cash flow forecasts within the financial service center to perform tasks such as liquidity planning or foreign exchange risk management. These forecasts are often generated in a decentralized fashion, where subsidiaries send out thousands of forecasts to corporate headquarters. These forecasts are then aggregated and provide the basis for corporatewide forecasting and planning tasks, such as liquidity planning or foreign exchange risk management ([1], [2], [3], [4], [5], [6]). The understanding of dependencies on forecasts is crucial for a reliable service of the finance department.

Usually, an initial forecast for a cash flow item is submitted several months or quarters before the cash flow's actual realization date and is then revised over time to consider novel or changed expectations of accountants. The sequence of initial forecast and adjusted forecasts is referred to as forecasting process, while the sequence of revisions is usually coined revisioning process or simply revisioning. Figure 1 visualizes the structure of an example five-step forecasting process. We denote the actual of cash flow item $i$ as $A(i)$ and $t$ the lead time of a forecast ${ }_{t} F(i)$ for $A(i)$ in time periods, e.g., quarters, to the actual date $(t=0)$. The initial forecast ${ }_{5} F(i)$ is delivered with a lead time of five periods and is revised four times until the last oneperiod-ahead forecast ${ }_{1} F(i)$ is generated. Hence, ${ }_{1} F(i)$ denotes the one-period ahead forecast for $A(i)$ (i.e., the last forecast), ${ }_{2} F(i)$ the two-periods ahead forecast.

Theory suggests that revisioning in efficient forecasting processes describes a random walk with zero correlation amongst revisions or between revision and error [7]. Non-random walks are expected to lead to higher error levels for reasons of statistical insufficiency due to cognitive biases. The application of this theory (e.g., [8], [9], [10], [11]) provides evidence that correlations are existent in many empirical datasets that are regularly associated with higher error levels. We argue that the identification of correlations-maybe at some aggregation levels or after the transformation of the raw forecast and actual items - has potentials to anticipating future adjustments, which might allow for accuracy improvements at longer forecast horizons.

However, we argue that such useful structures in revisioning might only be found at particular transformation and aggregation levels of the data, requiring the engineering of features from the data. The engineering of features, i.e., their aggregation, selection, and representation, requires a solid understanding and modeling of business and organizational structures and generally received scant attention in the IS-related literature so far ([12], [13], [14], [15]).

In this paper we will analyze whether regular patterns in the accountants' revisioning of cash flow 


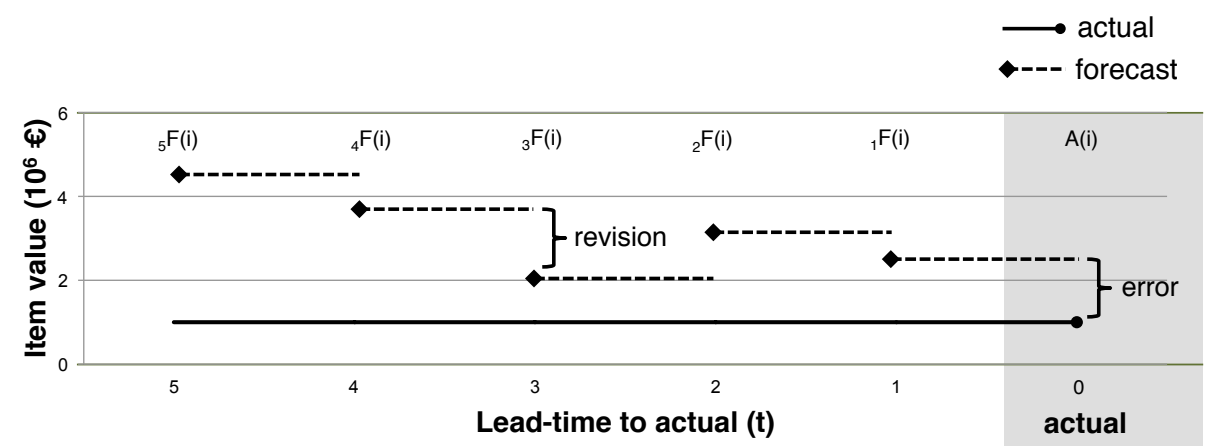

Figure 1: Temporal structure of cash flow forecasts ${ }_{t} \mathrm{~F}(\mathrm{i})$ with the corresponding actual cash flow A(i).

forecasts can be exploited to improve the accuracy of forecasts with higher lead time by considering expected subsequent adjustments, stated in the up-following research question:

\section{RQ: Is judgmental revisioning in cash flow forecasting affected by corporate targets or is random walk behavior identifiable in forecast revisions?}

The empirical analyses are based on a unique dataset of cash flow forecasts and actuals (the cash flow realizations) of 99 companies of a global corporation. As feature we consider a subsidiary's ratio of cash inflows and cash outflows cumulated over a fiscal year-a figure tightly related to a Key Performance Indicator (KPI) such as Earnings Before Interest, Taxes, Depreciation, and Amortization (EBITDA). The intuition is that meeting pre-arranged EBITDA targets is well incentivized and should therefore pave the way how cumulated actual ratios will develop over a year, and, as a consequence, how cash flow forecasts will (have to be) adjusted later on.

The empirical outcomes show that the direction and magnitude of the final revision of the aggregated cash flow forecasts can indeed be explained to a large extend by the relation between the ratio that results from current forecasts and a presumed accountants' earning target. This difference turns out to be a strong predictor for subsequent revision direction and volume.

The remainder of this paper is structured as follows. Section 2 introduces the theoretical framework. Section 3 describes our empirical dataset. The design of our empirical analysis together with our results is presented in Section 4. In Section 5, we discuss the implications of our work for potential forecast improvement and rethinking organizational structure.

\section{Related work}

One of the primary KPI for corporate performance is the EBITDA [16], which is important in the context of this paper, because it proxies a company's current operating profitability.

Organizational structures and dependencies can frame corporations and the work of managers - in our assumption forecasters with planned targets that affect realizations as well as forecasts and their adjustments - denoting our expression of an "organizational bias".

For instance, organizational biases can result by forecast deviations as pointed out in [17]. They identified "dividend thresholds" as an organizational bias. Within their analyses the organizational bias was related to the type of firms that are more likely to manage earnings. Further, [18] identified that firms manage earnings and managers seem to opportunistically capitalize on stock prices that include these manipulated earnings. In contrast to both of their findings over many firms on the stock market our paper analyzes the realizations and forecasts over many subsidiaries within one single corporation.

In the case of corporate internal forecasts, an organizational bias might be introduced by earnings being managed (by shifting actuals) to ensure that KPIs and planned annual targets are met. These tendencies to control cash flows by managing earnings are the result of operations made to ensure meeting specified targets in organizations ([19], [20]). Cash flow volumes are influenced by the considerations and motivations of various business functions; in particular, actuals are often shifted according to earnings management policies [21] and management incentives [22]. For instance, if annual return is expected to be too low, accountant's earnings management may result in shifts of cash outflow realizations-within the term of credit-forward to the next fiscal year to meet the appointed targets. 
These targets might be important to humans that try to achieve personal objectives (e.g., bonus payments by financial incentives) of predefined targets that rely on KPI figures, such as Earnings Before Interest and Taxes (EBIT), which can motivate to alter forecasts and their adjustments to maximize the personal profit [23]. Another example is stated in [24], where the author finds managed earnings that managers adjust in response to their bonus schemes. When organizational biases are expected to alter forecast revisions the forecast errors might increase, wherefore the potential of forecast correction is analyzed in [25]. The authors find that information of targets is indeed beneficial for the efficiency of forecasts, as well as for the correction of whole forecast processes.

Therefore, this paper argues that the organization's targets as a personal objective introduces organizational biases. These organizational biases are expected to alter forecasts, as they should exhibit the most recent information for the actual realizations. This argument will be analyzed on the empirical data from within the corporation.

\section{Available cash flow data}

The empirical data we use are a unique record of cash flow forecasts in the financial system of a large multinational corporation. The corporation is headquartered in Germany but has worldwide operating subsidiaries in different countries. With about 110,000 employees, the company is one of the largest corporations registered in Germany and generates annual revenues in the medium double-digit billion Euro range. The corporation has more than 300 separate legal entities, which include the subsidiaries. The subsidiaries are grouped into three divisions, based on their portfolios that are fundamentally different in business: "agricultural products" (AP), "health and pharmaceuticals" (HP), and "industrial materials" (IM). Entities with business portfolios belonging to more then one division are summarized under a fourth artificial division, "diverse" (DV).

Actuals and forecasts used stem from the corporate IT system and are available for the 99 largest subsidiaries. These subsidiaries participate in a forecast process where the local managers of the subsidiaries provide forecasts for future development and actual realizations. Delivered quarterly, the forecasts cover intervals with horizons of up to 15 months (five quarters). The available data range from January 2008 to December 2013 for actuals and from November 2007 to September 2013 for the corresponding forecasts. The generated forecasts of a subsidiary cover the subset of
Table 1: Summary of the available cash flow data.

\begin{tabular}{ccccc}
\hline Division & Subsidiaries & Currencies & Actual Series & Forecasts \\
\hline AP & 12 & 16 & 70 & 17,010 \\
HP & 19 & 26 & 146 & 29,070 \\
IM & 13 & 8 & 52 & 13,460 \\
DV & 53 & 37 & 216 & 42,820 \\
\hline All & 99 & 44 & 484 & 102,360 \\
\hline
\end{tabular}

currencies in which it issues and receives cash flows. Overall, 44 currencies are part of the dataset. In total, the raw dataset consists of 20,472 monthly cash flow actuals, each with five associated forecasts. The data is considered by the corporate financial controlling department as the highest reliable data source of the corporation and is used (after business adjustments for most recent developments) for the currency hedging of the corporation. Table 1 gives a brief summary of the dataset.

\section{Empirical analyses}

Before we describe the design and results of our empirical study, we will briefly review the intuition of the design we use.

We argue that the derived targets are tightly related to the percentage EBITDA margins of our company. This assumption is plausible for two reasons. First, derived EBITDA figures overall result from cash inflow and outflow. Second, this assumption is underpinned by the reported percentage EBITDA margin figures in the annual report, which are in line with the ranks of division ratios for December values. In the annual report 2011 the EBITDA margins listed of $22.8 \%$ (AP), $27.4 \%$ (HP), and $10.8 \%$ (IM). Official figures for division DV were not reported separately. In 2012, figures were: $24.0 \%$ (AP), $27.2 \%$ (HP), and $10.9 \%$ (IM). The figures in 2013 were comparable in magnitude, namely $25.5 \%$ (AP), $28.2 \%$ (HP), and $9.5 \%$ (IM). EBITDA figures are a primary KPI for corporate performance, and many corporations incentivize their managers to meet pre-arranged EBITDA targets.

We will now study whether a subsidiary's ratio of cash inflows and cash outflows cumulated over a fiscal year will drift towards the end-of-year ratios of the preceding years. The overall intuition is that meeting pre-arranged EBITDA targets might pave the way how aggregated actual ratios will develop over a year, and, as a consequence, how cash flow forecasts will (have to) be adjusted. 


\subsection{Proxy for return margin}

Let us introduce some additional notation used in our analysis. Reconsidering that we denote the actual of cash flow item $i$ as $A(i)$, and $t$ the lead time of a forecast ${ }_{t} F(i)$ for $i$, we use additional subscripts $m, y$, and $e$ to denote realization month, realization year, and the ID of the subsidiary associated with $i$. Superscript $g$ denotes the type of the actual $(g \in\{$ cash inflow (CI), cash outflow (CO) $\}$ ). Therefore, the indexation of an actual is in maximum $A_{e, y, m}^{g}(i)$. If an index is irrelevant or obvious in the context, we will omit to write the respective index for reasons of brevity.

For our return-related analyses at the organizational level, we require abstraction from the raw cash flow data in form of an aggregated perspective on cash inflows and cash outflows. As a proxy for percentage return within a fiscal year for a specific subsidiary $e$, we use the computed ratio $R$ of aggregated cash inflows and cash outflows in the $M$-th month of a year $Y$ and the $K$ months $(K<M)$ before $M$ as shown in Equation (1).

$$
R^{K}\left(A_{Y, M}\right)=\frac{\sum_{0 \leq j \leq K} A_{y=Y, m=M-j}^{g=C I}}{\sum_{0 \leq j \leq K} A_{y=Y, m=M-j}^{g=C O}}
$$

For instance, $R_{2010,12}^{2}$ refers to the ratio of all cash flows from October to December 2010. We omit the superscript $K$ if $K=M-1$ and denote $R\left(A_{Y, M}\right)$ as the ratio aggregating all realized cash flows in year $y=Y$ up to (and including) month $m=M$. As with individual actuals and forecasts, we use $F$ instead of $A$ when referring to ratios computed over forecasts. Since ratios are specific for an subsidiary $e$, for reasons of comparability we compute normalized ratios $R^{n}$, with values between zero and one per subsidiary. Normalized ratios are obtained by subtracting the minimum ratio within an subsidiary from $R$ and dividing by the difference of its maximum and minimum ratio.

We define $T\left(A_{E, Y}\right)$ as the suggested annual returns target (target ratio) of subsidiary $e=E$ in year $y=Y$, and $T^{n}\left(A_{E, Y}\right)$ as the normalized target. As targets are unknown (to us) but business developments are rather stable over the years, we estimate the target ratio in $y=Y$ by averaging the December ratios of the three preceding years. Finally, we define the last revision for ratios ${ }_{12} R^{n}=R^{n}\left({ }_{1} F\right)-R^{n}\left({ }_{2} F\right)$, and the difference from target with TargetDiff $=T^{n}(A)-R^{n}\left({ }_{1} F\right)$. For reasons of clarity: ratios and ratio revisions are neither stored in the database nor are they forecasted or adjusted directly. Ratios are computed from the cash flow items by us using (1).

\subsection{Revision analyses}

We expect a dependency of the target ratio $\left(T^{n}(A)\right)$ and revision $\left({ }_{12} R^{n}\right)$ together with a decrease of adjustments when approaching a suggested target ratio with a currently forecasted ratio. A schematic illustration of the expected relationships is shown in Figure 2.

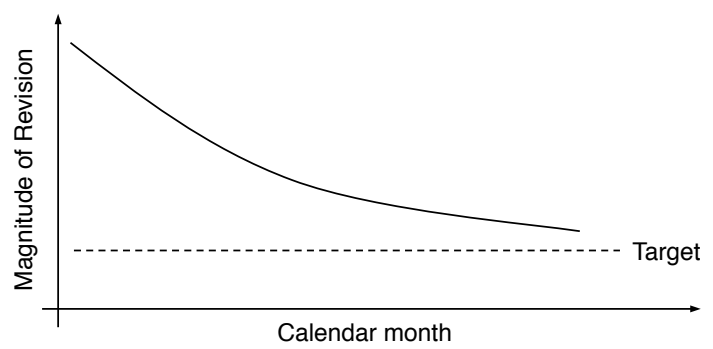

Figure 2: Hypothesized relationship between the magnitude of revision within the fiscal year.

Suggesting an accountant within a legal subsidiary to aim at achieving a pre-defined EBITDA, which strictly relates to a cumulated ratio of cash inflows and cash outflows, the magnitude of changes in ratio as a result of cash flow revisioning should increase with the distance to a presumed target. As we assume the target ratio to be met at the end-of-year, the difference from target should decline over the months of the year.

To test this relationship, we regress the magnitude of ${ }_{12} R^{n}$ on TargetDiff together with the actual month within a fiscal year (Month). Regression outcomes are shown in Table 2. The outcome shows that an expert's revisioning can indeed be partly explained by TargetDiff and Month. Changes in forecast ratios through a revisioning of cash flows increases with TargetDiff (the higher the distance of a forecasted ratio to the presumed target ratio, the higher the adjustments of the ratio through revisioning), and declines when approaching the end of a fiscal year. The significance of both estimates is surprising $\left({ }^{*} \mathrm{p}<0.1 ;{ }^{* *} \mathrm{p}<0.05\right.$; ${ }^{* * *} \mathrm{p}<0.01$; number of observations: 2,355 ), as this means that the magnitude of the final revisions of cash flows, at the aggregated ratio level, is predictable to some extend.

Table 2: Outcomes when regressing absolute change in forecast ratio through absolute difference from target and month.

\begin{tabular}{lr}
\hline Dep. Variables for $\left|{ }_{12} R^{n}\right|$ & \multicolumn{1}{c}{ Estimates } \\
\hline TargetDiff $\mid$ & $0.085^{* * *}$ \\
Month & $-0.005^{* * *}$ \\
Constant & $0.184^{* * *}$ \\
\hline
\end{tabular}


In order to operationalize these dependencies to improve cash flow prediction, we need to derive the direction of the final change in the forecasted ratio. Therefore, we regress ${ }_{12} R^{n}$ on the strength of TargetDiff and Month. Table 3 shows the result of the regression with significance levels $\left({ }^{*} \mathrm{p}<0.1 ;{ }^{* *} \mathrm{p}<0.05\right.$; ${ }^{* * *} \mathrm{p}<0.01$; number of observations: 2,355$)$.

Table 3: Results when regressing the revision of the forecasted ratio on the magnitude of difference from target and month.

\begin{tabular}{lc}
\hline Dep. Variables for ${ }_{12} R^{n}$ & \multicolumn{1}{c}{ Estimates } \\
\hline TargetDiff | & $0.054^{* *}$ \\
Month & $-0.004^{* * *}$ \\
Constant & $0.025^{*}$ \\
\hline
\end{tabular}

Results indicate that revision at the ratio level is significantly positively related to the magnitude of difference from target, indicating that forecasted ratios increase through the final revisioning cycle. The higher the absolute distance from $T^{n}(A)$, the more the cash flow forecasts $\left(R^{n}\left({ }_{1} F\right)\right)$ are adjusted to increase the ratio. In addition, over the months in a year the last revision $\left({ }_{12} R^{n}\right)$ decreases the forecasted ratio $\left(R^{n}\left({ }_{1} F\right)\right)$. These results hint at experts adjusting their cash flows in a way to reach a position above $T^{n}(A)$. Forecasted ratios below $T^{n}(A)$ are revised upwards, with adjustments getting smaller when approaching $T^{n}(A)$. Considering the negative estimate of Month, this leads to approaching $T^{n}(A)$ towards the end of a year.

However, the interpretation of the regression outcomes when a forecasted ratio is already above the suggested target is challenging. Therefore, we analyze how forecasted ratios are revised when suggested targets are already reached with the forecast compared to forecasts that are below target. With Sign(TargetDiff) as binary variable indicating whether $R^{n}\left({ }_{1} F\right)$ is above or below the suggested target $T^{n}(A)$, we regress the final revision ${ }_{12} R^{n}$ on Sign(TargetDiff). Regression results are shown in Table 4 . The significance of the negative estimate indicates that $R^{n}\left({ }_{1} F\right)$ decrease when $T^{n}(A)$ is already met and increased when $R^{n}\left({ }_{1} F\right)$ is below $T^{n}(A)\left({ }^{*} \mathrm{p}<0.1\right.$; ${ }^{* *} \mathrm{p}<0.05$; ${ }^{* * *} \mathrm{p}<0.01$; number of observations: 2,355$)$.

Table 4: Results when regressing the last ratio revision on Sign(TargetDiff).

\begin{tabular}{ll}
\hline Dep. Variables for ${ }_{12} R^{n}$ & Estimate \\
\hline Sign(TargetDiff) & $-0.081^{* * *}$ \\
\hline
\end{tabular}

\subsection{Summary and discussion}

Overall, these results show that forecasting processes do not describe random walks and provide strong indication that cash flow ratios are adjusted to converge to predefined target ratios. The difference of the forecast to this target turns out to be a strong predictor for subsequent revision direction and volume. This allows for anticipating the final revision and therefore the upcoming expert forecasts to some extend. Knowledge of how forecasts will be adjusted later on by experts allows improving longer-term forecasts, considering that forecast accuracy overall increases with decreasing lead time. For instance, we can model the last revision ${ }_{12} R^{n}$ at $t=2$ and therefore partially anticipate the final forecast $R^{n}\left({ }_{1} F\right)$ in advance.

Therefore, the answer for the research question is that strategic targets can explain judgmental revisioning, which rejects the expected random walk behavior.

The answer is in line with the results of [19], [26], while our results point out the avoidance of negative target surprises (as a threshold for the organizational bias of earnings margin) for company internal cash flows. However, our results extend their perspective as we can analyze forecasts with different lead times and relate the revision to the threshold. We assume that the results were influenced by various organizational effects, such as for instance noted in [27] or [23]. Overall, we assume managed earnings to be causal for our results, which materializes in the presented target.

The results are expected to be valid for the over 200 other entities of the corporation. These entities possess similar business structures, but mainly differ in entity-size (have smaller transactions when measured in Euro equivalent volumes) and the availability of the data. We and the managers of the finance department are confident that the results are transferable to different companies and with a likewise business structure, earnings management, and strategic targets.

\section{Conclusions and outlook}

We analyzed empirical cash flow forecast data of a large multinational corporation and provide the first study on patterns in cash flow forecast revisioning processes related to management targets. The analyses reveal predictable patterns of how the ratios of cumulated cash inflows and cash outflows are adjusted over time. The results hint to accountants' targets related to EBITDA that pave the way how actuals are adjusted over the year, and, as a consequence, how forecasts are revised.

From a managerial perspective, our results provide 
new insights and implications for the services of corporate financial controlling. One the one hand, the found pattern can lead to automated correction of longer-term forecasts by anticipation upcoming revision behavior of experts. On the other hand, probably a more interesting question might be why experts do not consider the upcoming revisioning earlier in a forecasting process, as their adjustments can-to some extend-be anticipated by statistical means. One potential explanation might be that these adjustments are not strictly related to the operational business figures and developments the experts should use for their forecasts. Changes in actuals can also be related to accountants' earnings management activities to meet pre-defined EBITDA, and experts might be not fully aware of these targets and earnings management activities. It should be noted that forecasters are encouraged to derive independent prediction that are not aligned with the local controller. However, these findings underpin the necessity to a better understanding of the interplay of organizational structures and forecasting processes to provide an accurate, and a reliable financial system within a company.

Despite the potential causes for the predictability of the cash flow forecasts at the cumulated ratio level, our results indicate huge potentials for improving longer-term cash flow forecasts and corporate risk assessment that uses the forecast data in the financial system. For instance, for companies operating in two currencies only, corrections at the ratio level are directly related to corrections of foreign exchange exposure, where considering the upcoming adjustments within the financial services would directly allow for improving overall exposure forecasts to reduce either unhedged risks or hedgingcosts.

\section{References}

[1] J. D. Martin and G. E. Morgan, "Financial Planning Where the Firm's Demand for Funds is Nonstationary and Stochastic," Management Science, vol. 34, no. 9, 1988, pp. 1054-1066.

[2] R. M. Stulz, "Managerial Discretion and Optimal Financing Policies," Journal of Financial Economics, vol. 26, no. 1, 1990, pp. 3-27.

[3] C. Kim, D. Mauer, and A. Sherman, "The Determinants of Corporate Liquidity: Theory and Evidence," Journal of Financial and Quantitative Analysis, vol. 33, no. 3, 1998, pp. 335-359.

[4] J. R. Graham and C. R. Harvey, "The Theory and Practice of Corporate Finance: Evidence from the Field," Journal of Financial Economics, vol. 60, no. 2, 2001, pp. 187-243.

[5] H. Almeida, M. Campello, and M. S. Weisbach, "The Cash Flow Sensitivity of Cash," Journal of Finance, vol. 59, no. 4, 2004, pp. 1777-1804. [Online]. Available: http://dx.doi.org/10.1111/j.1540-6261.2004.00679.x

[6] S. S. Lim and H. Wang, "The Effect of Financial Hedging on the Incentives for Corporate Diversification: The Role of Stakeholder Firm-Specific Investments," Journal of Economic Behavior \& Organization, vol. 62, no. 4, 2007, pp. 640-656.

[7] W. D. Nordhaus, "Forecasting Efficiency: Concepts and Applications," The Review of Economics and Statistics, vol. 69 , no. 4,1987 , pp. 667-674.

[8] M. Lawrence and M. O'Connor, "Sales Forecasting Updates: How Good are They in Practice?" International Journal of Forecasting, vol. 16, no. 3, 2000, pp. 369382. [Online]. Available: http://ideas.repec.org/a/eee/intfor/ v16y2000i3p369-382.html

[9] M. Ashiya, "Testing the Rationality of Japanese GDP Forecasts: The Sign of Forecast Revision Matters," Journal of Economic Behavior \& Organization, vol. 50, no. 2, 2003, pp. 263-269.

[10] J. Dovern and J. Weisser, "Accuracy, Unbiasedness and Efficiency of Professional Macroeconomic Forecasts: An Empirical Comparison for the G7," International Journal of Forecasting, vol. 27, no. 2, 2011, pp. 452465. [Online]. Available: http://ideas.repec.org/a/eee/intfor/ v27y2011i2p452-465.html

[11] B. Deschamps and C. Ioannidis, "Can Rational Stubbornness Explain Forecast Biases?" Journal of Economic Behavior \& Organization, vol. 92, 2013, pp. 141151. [Online]. Available: http://ideas.repec.org/a/eee/jeborg/ v92y2013icp141-151.html

[12] L. A. Gordon and D. Miller, "A contingency framework for the design of accounting information systems," Accounting, Organizations and Society, vol. 1, no. 1, 1976, pp. 59-69.

[13] R. Fildes, P. Goodwin, and M. Lawrence, "The Design Features of Forecasting Support Systems and Their Effectiveness," Decision Support Systems, vol. 42, no. 1, Oct. 2006, pp. 351-361.

[14] J. Han, J. Pei, and M. Kamber, Data Mining: Concepts and Techniques. Elsevier, 2011.

[15] F. Knöll, V. Dorner, and T. Setzer, "Relating Cash Flow Forecast Errors to Revision Patterns," in Multikonferenz Wirtschaftsinformatik (MKWI) 2016: Prescriptive Analytics in IS, vol. 2. Universitätsverlag Ilmenau, 2016, pp. 12171228.

[16] B. Marr, Key Performance Indicators (KPI): The 75 Measures Every Manager Needs to Know. Pearson UK, 2012.

[17] N. D. Daniel, D. J. Denis, and L. Naveen, "Do Firms Manage Earnings to Meet Dividend Thresholds?" Journal of Accounting and Economics, vol. 45, no. 1, 2008, pp. 2-26.

[18] D. Bergstresser, M. Desai, and J. Rauh, "Earnings manipulation, pension assumptions, and managerial investment 
decisions," The Quarterly Journal of Economics, vol. 121, no. 1, 2006, pp. 157-195.

[19] D. Burgstahler and M. Eames, "Management of Earnings and Analysts' Forecasts to Achieve Zero and Small Positive Earnings Surprises," Journal of Business Finance \& Accounting, vol. 33, no. 5-6, 2006, pp. 633-652.

[20] F. Degeorge, J. Patel, and R. Zeckhauser, "Earnings Management to Exceed Thresholds," Journal of Business, vol. 72, no. 1, 1999, pp. 1-33. [Online]. Available: http://www.jstor.org/stable/10.1086/209601

[21] D. Burgstahler and I. Dichev, "Earnings Management to Avoid Earnings Decreases and Losses," Journal of Accounting and Economics, vol. 24, no. 1, 1997, pp. 99-126.

[22] R. W. Holthausen, D. F. Larcker, and R. G. Sloan, "Annual Bonus Schemes and the Manipulation of Earnings," Journal of Accounting and Economics, vol. 19, no. 1, 1995, pp. 29-74.

[23] F. Guidry, A. J. Leone, and S. Rock, "Earnings-Based
Bonus Plans and Earnings Management by Business-Unit Managers," Journal of Accounting and Economics, vol. 26, no. 1,1999 , pp. 113-142.

[24] P. M. Healy, "The Effect of Bonus Schemes on Accounting Decisions," Journal of Accounting and Economics, vol. 7, no. 1-3, 1985, pp. 85-107.

[25] F. Knöll and V. Simko, "Organizational Information improves Forecast Efficiency of Correction Techniques," in Proceedings of the 17th Conference Information Technologies - Applications and Theory (ITAT), Computational Intelligence and Data Mining (WCIDM 2017), vol. 1885, 2017.

[26] J. Jacob and B. N. Jorgensen, "Earnings Management and Accounting Income Aggregation," Journal of Accounting and Economics, vol. 43, no. 2, 2007, pp. 369-390.

[27] S. Roychowdhury, "Earnings Management Through Real Activities Manipulation," Journal of Accounting and Economics, vol. 42, no. 3, 2006, pp. 335-370. 